\title{
The Stability of Comorbid Psychiatric Disorders: A 7 Year Follow Up of Children with Pervasive Developmental Disorder-Not Otherwise Specified
}

\author{
C. Verheij ${ }^{1}$ A. Louwerse ${ }^{1,2} \cdot$ J. van der Ende $^{1}$ - M. L. J. M. Eussen ${ }^{1,2}$. \\ A. R. Van Gool $^{2}$ - F. Verheij ${ }^{1}$ - F. C. Verhulst ${ }^{1}$ - K. Greaves-Lord ${ }^{1,2}$
}

Published online: 12 October 2015

(c) The Author(s) 2015. This article is published with open access at Springerlink.com

\begin{abstract}
The current study was a 7-year follow-up of 74 6-12 year old children with Pervasive Developmental Disorder-Not Otherwise Specified. We examined the rates and 7 year stability of comorbid psychiatric diagnoses as ascertained with the Diagnostic Interview Schedule for Children: Parent version at ages 6-12 and again at ages 12-20. Also, we examined childhood factors that predicted the stability of comorbid psychiatric disorders. The rate of comorbid psychiatric disorders dropped significantly from childhood $(81 \%)$ to adolescence $(61 \%)$. Higher levels of parent reported stereotyped behaviors and reduced social interest in childhood significantly predicted the stability of psychiatric comorbidity. Re-evaluation of psychiatric comorbidity should be considered in clinical practice, since several individuals shifted in comorbid diagnoses.
\end{abstract}

Keywords Autism spectrum disorder - Pervasive developmental disorders $\cdot$ Comorbidity $\cdot$ Follow-up

\section{Introduction}

Psychiatric comorbidities in children with autism spectrum disorder (ASD) are rather a rule than an exception (Abdallah et al. 2011; De Bruin et al. 2007; Ghaziuddin et al. 1998; Joshi et al. 2010; Leyfer et al. 2006; Simonoff et al.

K. Greaves-Lord

k.greaves-lord@erasmusmc.nl

1 Department of Child and Adolescent Psychiatry/Psychology, Erasmus Medical Center/Sophia Children's Hospital, Dr. Molewaterplein 60, 3015 GJ Rotterdam, The Netherlands

2 Yulius Academy, Yulius, Organisation of Mental Health, Dordrecht, The Netherlands
2008, 2013; Van Steensel et al. 2013). In 2007, we showed that at least one comorbid psychiatric disorder was present in $81 \%$ of the children with Pervasive Developmental Disorder-Not Otherwise Specified (PDD-NOS); $62 \%$ had a comorbid disruptive behavior disorder, and $55 \%$ fulfilled criteria of an anxiety disorder (De Bruin et al. 2007). Little is however known about the stability of these childhood psychiatric comorbidities in ASD towards adolescence and adulthood. Adolescence is marked by many social, psychological and physical changes in the individual. These changes are often accompanied by an increase in emotional or behavioral problems (Dahl 2004). The issues may be amplified in ASD as a result of their particular difficulties in adapting to change. Simonoff et al. (2013) have shown that comorbid psychiatric symptoms in ASD are persistent from childhood to adolescence, with domain-specific correlations (i.e. among one specific type of symptoms, such as anxiety) ranging from 0.33 to 0.58 across the period of 12-16 year old. However, the authors investigated the stability of continuous questionnaire measures rather than the stability of diagnostic categories. Information on the stability of diagnoses based on in-depth interviews with trained professionals can give us additional information on the impact of problems on everyday functioning.

Therefore, the current prospective study firstly investigated the stability from childhood into adolescence of comorbid DSM-IV defined psychiatric disorders in children with PDD-NOS on whom we previously reported childhood comorbidity rates (De Bruin et al. 2007).

It is important to know which individuals are at risk of persistent comorbid psychiatric disorders throughout adolescence. For this purpose, it is important to examine factors in childhood that may predict the persistence of comorbid disorders into adolescence. Several putative predictors can be derived from the literature. Individual 
factors, such as age, gender, intelligence and type and/or severity of ASD symptoms, might influence outcome in adolescence. Firstly, the variation in age of onset varies among comorbid disorders (e.g. Hepburn et al. 2014), thus, age might explain differences in outcome. Secondly, gender might also be an important predictive factor, since in the general population, gender differences of psychiatric disorders are often described. For example, anxiety symptoms in adolescence and depression in late adolescence are reported at higher prevalence in girls compared to boys (Van Oort et al. 2009; Costello et al. 2003; Petersen et al. 1991; Hankin et al. 1998). Disorders such as attention deficit/hyperactivity disorder (ADHD) and conduct disorder (CD) are described to be more often present in boys than in girls (Costello et al. 2003; Arnold 1996; APA 2000). Thirdly, intelligence might be a predictive factor since children in the general population with an Intelligence Quotient (IQ) below 80 tended to have more emotional and behavioral problems compared to children with an IQ above 80 (Dekker et al. 2002). In contrast, studies regarding children with ASD often report high rates of cooccurring disorders in individuals with both high and low IQs (Simonoff et al. 2008; Leyfer et al. 2006). Fourthly, type and severity of ASD symptoms might also influence the comorbid disorders. In our previous cross-sectional study we showed that children with PDD-NOS and both internalizing and externalizing disorders had more parent-rated problems with executive functioning (i.e. orientation in time, place and activity), more problems with tuning-into the social situation and more stereotyped behaviors than those with PDD-NOS without comorbid psychiatric disorders (De Bruin et al. 2007). Moreover, individuals with internalizing and externalizing disorders in childhood are at risk for developing other co-occuring disorders during adolescence (Goodwin et al. 2004; Bittner et al. 2007; Bussing et al. 2010). However, more studies are needed to evaluate the development of comorbid disorders in individuals with ASD. Therefore, in the current study, we also investigated whether gender, age, IQ, type and severity of parent-rated ASD symptoms, type of initial comorbid psychiatric disorder, intermediate mental health care and medication were associated with the stability of comorbid psychiatric disorders.

\section{Methods}

\section{Sample and Procedure}

Participants were 74 individuals with PDD-NOS, who were initially referred for diagnostic evaluation to the Department of Child and Adolescent Psychiatry/Psychology of the Erasmus Medical Center-Sophia Children's Hospital between July 2002 and September 2004. Eighty eight percent of the sample was male, the mean IQ was $93(S D=16.96)$, $90.5 \%$ had a Dutch nationality. $45 \%$ of fathers and $46 \%$ of mothers had had a post-secondary school education; $84 \%$ of fathers and $57 \%$ of mothers had had a paid job in the previous 2 years, and most were in paid employment at the time of this study ( $83 \%$ of fathers and $54 \%$ of mothers). Of 54 participants, their living situation was known; $87 \%$ were living at home with their parent(s) at wave 2 .

Inclusion criteria were: (1) meeting the research criteria for PDD-NOS in childhood ( $\mathrm{n}=94$; De Bruin et al. 2007; Buitelaar et al. 1999), and (2) participation of the parents in the Diagnostic Interview Schedule for Children: Parent version ([DISC-IV-P], Ferdinand and Van der Ende 1998; Shaffer et al. 2000), in childhood ( $\mathrm{n}=94$, wave 1 ; age 6-12, $M=9.02, S D=1.81)$ and 7 years later, in adolescence ( $\mathrm{n}=74$, wave 2 ; age $12-20, M=16.00, S D=1.92$ ). The average follow-up time between the DISC-IV-P at wave 1 and wave 2 was 6.95 years (range $5.58-8.82$ year; $S D: 0.64$ ).

The 74 individuals whose parents participated at both wave 1 and wave 2 did not significantly differ in terms of gender, age, nationality, parental nationality, socio-economic status and number of DISC-IV diagnoses from individuals whose parents participated only at wave $1(\mathrm{n}=94)(p>.05)$. However, individuals whose parents participated at both wave 1 and wave 2 had significantly higher IQ-scores $(M=92.96, S E=16.96)$ versus individuals whose parents only participated at wave 1 $[M=83.94, S E=16.88 ; t(86)=-2.01, p=.05]$.

\section{Measures}

\section{Diagnostic Interview Schedule for Children IV Parent Version (DISC-IV-P)}

The DISC-IV-P (Shaffer et al. 2000) is a structured parent interview determining 1- and 12-month DSM-IV-TR (APA 2000) psychiatric disorders in children and adolescents. Parents were interviewed by phone by trained and certified research assistants. The DISC-IV-P was used to assess internalizing disorders (i.e. anxiety and mood disorders) and externalizing disorders (i.e. disruptive disorders) at wave 1 and 2 and was scored using the internet software (Steenhuis et al. 2009) of the Dutch translation of the DISC-IV-P (Ferdinand and Van der Ende 1998). The anxiety disorder module consists of nine disorders; social phobia ( $\mathrm{SoPh}$ ), separation anxiety disorder (SAD), specific phobia (SP), panic disorder (PD), agoraphobia (AG), generalized anxiety disorder (GAD), selective mutism (SM), obsessive compulsive disorder (OCD) and posttraumatic stress disorder (PTSD). The mood disorder module consists of major depressive episode (MDD), dysthymia, and manic/hypomanic episode. The disruptive behaviors are subdivided in the DISC-IV-P in: ADHD, oppositional defiant disorder (ODD) and $\mathrm{CD}$. 


\section{Children's Social Behavior Questionnaire (CSBQ)}

To examine whether the level and type of parent-rated ASD symptoms in childhood (i.e. wave 1) was associated with the stability of comorbidity, the CSBQ was used. The CSBQ is a parental questionnaire, which contains 49 items about a broad range of features that are typical for ASD (Hartman et al. 2006; Luteijn et al. 1998). The items are scored on a three-point scale (i.e. 0: behavior does not apply; 1: behavior sometimes or somewhat applies; 2: behavior clearly or often applies to the child). The CBSQ consists of six subscales; (1) "not optimally tuned to the social situation", (2) "reduced contact and social interest", (3) "orientation problems in time, place or activity", (4) "difficulties in understanding social information", (5) "stereotyped behavior" and (6) "fear of and resistance to changes". Good test-retest, inter-rater reliability and internal consistency have been reported for this measure (Hartman et al. 2006). Across our sample, internal consistency of CBCQ data was good, with Cronbach's alpha's ranging from 0.79 to 0.88 .

\section{Intelligence Quotient (IQ)}

To examine whether IQ in childhood (i.e. wave 1) was associated with the stability of comorbidity, the Wechsler Intelligence Scale for Children-Revised (WISC-R; Wechsler 1974) was administered. This instrument comprises a verbal scale (VIQ) and a performance scale (PIQ) together forming a total scale (TIQ). The Dutch version of the WISC-R has been demonstrated to be sufficiently reliable and valid (Van Haasen et al. 1986).

\section{Intermediate Use of Mental Health Care and Medication}

To assess the use of mental health care and medication between wave 1 and 2 , a parent questionnaire was administered at wave 2 (Amone-P'Olak et al. 2010). Eight questions concerned use of mental health care with regard to emotional and/or behavioral problems of the child. These items were scored as 0 (i.e. not used) or 1 (i.e. used). If any of these items was scored 1 , the variable 'mental health care' was scored 1. Parents were also asked if their child had used psychotropic medication in the past 2 weeks. This variable was also scored as 0 (i.e. not used) or 1 (i.e. used).

\section{Self-Reported Emotional and Behavioral Problems (Youth Self Report; YSR)}

The YSR is an instrument of the Achenbach System of Empirically Based Assessment (ASEBA) that has good reliability and validity (Achenbach and Rescorla 2001), and has been used previously with cognitively able individuals with ASD (Schroeder et al. 2011; Hurtig et al. 2009). Adolescents rate their behavior over the preceding 6 months, items being scored on a three-point scale, with responses: $0=$ not true, $1=$ somewhat or sometimes true, $2=$ very true or often true. The problem items are scored on empirically based syndromes that were derived by factor analyses. In the current study, the YSR was only administered at wave 2, and we analyzed scores on the following scales: Anxious/Depressed, Withdrawn/Depressed, Somatic Complaints, Attention Problems, Rule-Breaking Behavior and Aggressive Behavior (i.e. the scales that are most similar to the content of the DISC-P). T-scores of 65 or higher reflect scores in the subclinical range, while $t$-scores of 70 or higher reflect scores in the clinical range.

\section{Data Analysis}

Firstly, the rates of comorbid psychiatric disorders were calculated at wave 1 and wave 2 . The significance of putative changes in the prevalence rates was tested using McNemar tests. To investigate the stability of comorbid psychiatric disorders from childhood to adolescence, we made a cross-table of the presence or absence of comorbid disorders at wave 1 and wave 2 (i.e. proportions of individuals in the following groups: 1: "persistent presence", 2: "from presence to absence", 3: "from absence to presence" and 4: "persistent absence"). To graphically illustrate whether stability was domain-specific, the number of individuals with either continuous or discontinuous disorders from wave 1 to wave 2 were demonstrated.

To examine whether gender, age, IQ, level and type of parent-rated ASD symptoms (CSBQ scores), intermediate mental health care and medication were associated with the stability of psychiatric disorders, we compared the group with persistent disorders $(\mathrm{n}=38$, "persistent presence") with the group that changed from disorder to no disorder ( $\mathrm{n}=22$, "from presence to absence") and the group with persistent absence of disorders $(\mathrm{n}=7$, "persistent absence") with the group that changed from no disorder to disorder ( $\mathrm{n}=7$, "from absence to presence"). Comparisons were performed using t-tests for continuous variables (i.e. IQ, age, CSBQ scores) and Chi Square tests for categorical variables (i.e. gender, mental health care use and the use of psychotropic medication). For the smaller groups "persistent absence" and "from absence to presence", nonparametric testing (i.e. Mann-Whitney $U$ test and Binomial test) was used.

To be able to further interpret the parent-reported DISC data in the light of self-reported emotional and behavioral problems in adolescence, we post hoc explored the proportions of individuals who scored in the subclinical $(\geq t 65)$ and clinical $(\geq t 70)$ range of the YSR at wave 2. 


\section{Results}

\section{Prevalence of Comorbid Psychiatric Disorders in Childhood and Adolescence}

The prevalence of all separate comorbid disorders at wave 1 and wave 2 are presented in Table 1. Internalizing disorders significantly decreased over time; $60 \%$ of the individuals in childhood met criteria for at least one internalizing disorder, in adolescence this rate dropped to $35 \%$ [McNemar; $x^{2}$ $(\mathrm{n}=74)=10.32, p=.001]$. Note that especially the rate of anxiety disorders, significantly decreased from childhood (i.e. $55 \%)$ to adolescence (i.e. $31 \%$ ) [McNemar; $x^{2}$ $(\mathrm{n}=74)=10.32, p=.001]$; the rate of mood disorders approximately stayed the same. The rates for externalizing (i.e. disruptive) disorders did not significantly change from childhood (i.e. $61 \%$ ) to adolescence (i.e. $51 \%$ ). Overall, the number of individuals who had a comorbid psychiatric disorder significantly changed from childhood to adolescence $\left[\right.$ McNemar; $\left.x^{2}(\mathrm{n}=74)=6.76, p=.01\right]$; during childhood,
$81 \%$ of the individuals had one or more comorbid psychiatric disorder, during adolescence at least one comorbid psychiatric disorder was present in $61 \%$ of the individuals.

\section{Stability of Comorbid Psychiatric Disorders}

Figure 1 shows the proportions of individuals in the following groups (1) "persistent presence", (2) "from presence to absence", (3) "from absence to presence" and (4) "persistent absence". Of the individuals who had at least one comorbid psychiatric disorder in childhood $(\mathrm{n}=60)$, $63 \%$ still had at least one comorbid psychiatric disorder in adolescence $(\mathrm{n}=38)$, whereas $37 \%$ of the individuals no longer met criteria for a comorbid psychiatric disorder in adolescence $(n=22)$. Of the individuals who had no comorbid psychiatric disorder in childhood $(\mathrm{n}=14), 50 \%$ $(\mathrm{n}=7)$ stayed free of a comorbid psychiatric disorder in adolescence, whereas $50 \%(\mathrm{n}=7)$ of the individuals developed at least one comorbid psychiatric disorder in adolescence.

Table 1 Prevalence of comorbid disorders according to the DISC-IV-P $(n=74)$

\begin{tabular}{|c|c|c|c|c|c|c|}
\hline \multirow[t]{2}{*}{ Disorder } & \multirow{2}{*}{$\begin{array}{l}\text { Wave } 1 \text { (age } 6-12 \text { ) } \\
\% \text { of individuals }\end{array}$} & \multirow{2}{*}{$\begin{array}{l}\text { Wave } 2 \text { (age } 12-20 \text { ) } \\
\% \text { of individuals }\end{array}$} & \multirow[t]{2}{*}{$p$} & \multicolumn{3}{|c|}{ Transitions in diagnosis } \\
\hline & & & & $\begin{array}{l}\text { Stable }^{\mathrm{a}} \\
\mathrm{n}\end{array}$ & $\begin{array}{l}\text { Out of } \\
n\end{array}$ & $\begin{array}{l}\text { Into }^{c} \\
n\end{array}$ \\
\hline Anxiety disorders & 55.4 & 31.1 & 0.001 & 18 & 23 & 5 \\
\hline Social phobia & 10.8 & 1.4 & 0.02 & 1 & 7 & 0 \\
\hline Separation anxiety disorder & 6.8 & 4.1 & 0.69 & 1 & 4 & 2 \\
\hline Specific phobia & 40.5 & 25.7 & 0.04 & 12 & 18 & 7 \\
\hline Agoraphobia & 5.4 & 2.7 & 0.69 & 0 & 4 & 2 \\
\hline Panic disorder without agoraphobia & 1.4 & 0.0 & 1.00 & 0 & 1 & 0 \\
\hline Panic disorder with agoraphobia & 0.0 & 1.4 & 1.00 & 0 & 0 & 1 \\
\hline Generalized anxiety disorder & 6.8 & 4.1 & 0.73 & 0 & 5 & 3 \\
\hline Selective mutism & 0.0 & 0.0 & - & 0 & 0 & 0 \\
\hline Obsessive compulsive disorder & 6.8 & 8.1 & 1.00 & 0 & 5 & 6 \\
\hline Posttraumatic stress disorder & 0.0 & 1.4 & 1.00 & 0 & 0 & 1 \\
\hline Mood disorders & 12.2 & 10.8 & 1.00 & 3 & 6 & 5 \\
\hline Major depression & 8.1 & 10.8 & 0.73 & 3 & 3 & 5 \\
\hline Dysthymic disorder & 2.7 & 0.0 & 0.50 & 0 & 2 & 0 \\
\hline Mania & 4.1 & 1.4 & 0.63 & 1 & 3 & 1 \\
\hline Hypomania & 2.7 & 0.0 & 0.50 & 0 & 2 & 0 \\
\hline Disruptive disorders & 60.8 & 51.4 & 0.28 & 26 & 19 & 12 \\
\hline ADHD, combined type & 20.3 & 8.1 & 0.05 & 2 & 13 & 4 \\
\hline ADHD, inattentive type & 13.5 & 25.7 & 0.08 & 4 & 6 & 15 \\
\hline ADHD, hyperactive/impulsive type & 10.8 & 5.4 & 0.39 & 0 & 8 & 4 \\
\hline Oppositional defiant disorder & 35.1 & 27.0 & 0.29 & 12 & 14 & 8 \\
\hline Conduct disorder & 9.5 & 2.7 & 0.18 & 0 & 7 & 2 \\
\hline
\end{tabular}

Bold values are statistically significant $(p<0.05)$

${ }^{\text {a }}$ Identical $=$ Participants had the same diagnosis at $\mathrm{T} 1$ and at $\mathrm{T} 2$

${ }^{\mathrm{b}}$ Out of $=$ Participants did have the diagnosis at T1, but no longer at $\mathrm{T} 2$

${ }^{\mathrm{c}}$ Into $=$ Participants did not have the diagnosis at $\mathrm{T} 1$, but did have the diagnosis at $\mathrm{T} 2$ 


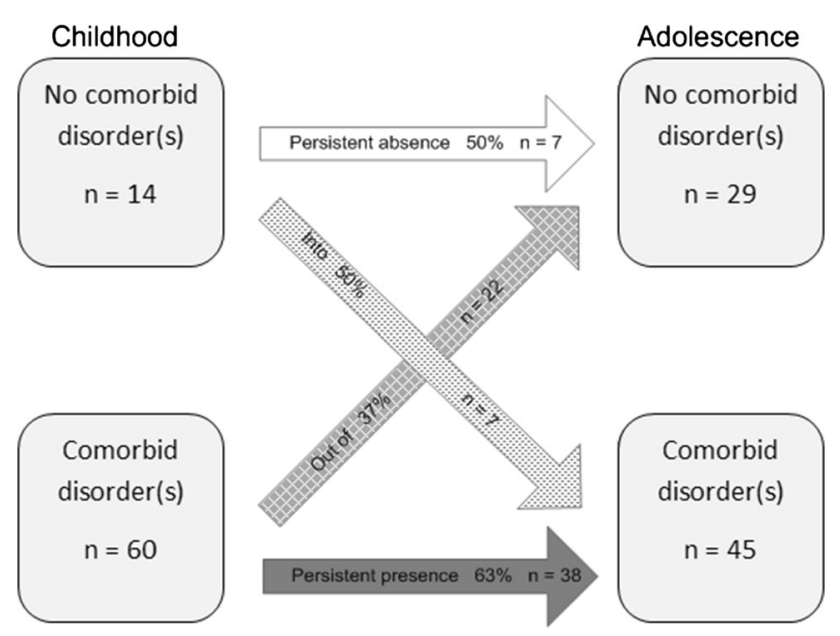

Fig. 1 Stability of comorbid psychiatric disorders from childhood to adolescence

Figure 2 illustrates the domain-specific stability; the amount of individuals with continuous or discontinuous (i.e. other type of) disorders from wave 1 to wave 2 .

\section{Predictors of Stability}

The childhood characteristics of individuals in the "persistent presence" group $(\mathrm{n}=38)$ versus the "presence to absence" group $(\mathrm{n}=22)$ were compared to examine factors associated with stability of comorbid psychiatric disorders (Table 2). No significant differences were found regarding age, gender, IQ, intermediate mental health care and psychotropic medication.

As for level and type of symptoms of ASD, individuals with persistent comorbidity had significant more parentreported stereotyped behaviors $[t(53.465)=3.66$, $\left.p=.001, R_{N}^{2}=0.226\right]$ and reduced contact and social interest $\left[t(57)=2.15, p=.04, R_{N}^{2}=0.10\right]$ in childhood, than individuals who lost their comorbid psychiatric diagnosis during adolescence.

To further clarify this finding, a post hoc test was performed to reveal possible predictors specific for persistent externalizing versus persistent internalizing disorders. In both cases, only parent-reported stereotyped behavior was a significant predictive factor for persistence of the same psychiatric comorbidities [i.e. respectively $(t(40)=$ $-2.953, p=.005) ;(t(39)=-3.287, p=.002)]$.

The childhood characteristics of the "persistent absence" group $(\mathrm{n}=7)$ were compared to the "absent to present" group $(\mathrm{n}=7)$ on factors associated with stability of comorbid psychiatric disorders (Table 2). No significant differences were found in age, gender, IQ, level or type of ASD symptomology, intermediate mental health care or use of psychotropic medication.

\section{Self-Reported Emotional and Behavioral Problems}

Table 3 shows the proportions of individuals who scored in the subclinical $(\mathrm{t} 65-\mathrm{t} 70)$ and clinical $(\geq \mathrm{t} 70)$ range of the YSR at wave 2 .

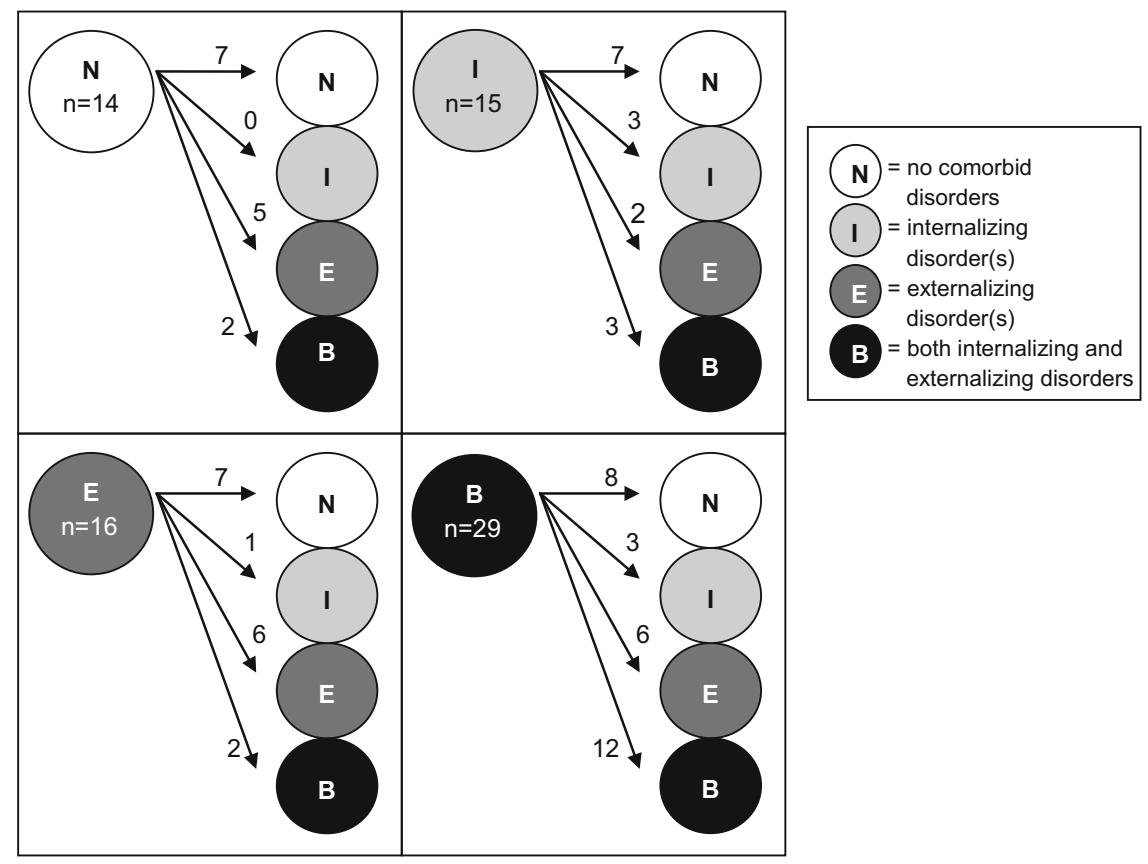

Fig. 2 Transitions in type of comorbid psychiatric disorders from childhood to adolescence. This figure shows the different types of transitions from $\mathrm{T} 1$ comorbid diagnoses (left circle in each square) to T2 comorbid diagnoses (right circles in each square) 
Table 2 Childhood predictors compared between developmental course groups

\begin{tabular}{|c|c|c|c|c|c|c|}
\hline & $\begin{array}{l}\text { Persistent } \\
\text { presence of } \\
\text { psychiatric } \\
\text { comorbidity } \\
(\mathrm{n}=38)\end{array}$ & $\begin{array}{l}\text { From presence to } \\
\text { absence of } \\
\text { psychiatric } \\
\text { comorbidity } \\
(\mathrm{n}=22)\end{array}$ & $p$ & $\begin{array}{l}\text { Persistent } \\
\text { absence of } \\
\text { psychiatric } \\
\text { comorbidity } \\
(n=7)\end{array}$ & $\begin{array}{l}\text { From absence to } \\
\text { presence of } \\
\text { psychiatric } \\
\text { comorbidity } \\
(n=7)\end{array}$ & $p$ \\
\hline Gender: $\%$ boys & $84 \%$ & $96 \%$ & 0.19 & $71 \%$ & $100 \%$ & 0.38 \\
\hline Age (SD) & $9.06(1.66)$ & $8.94(2.10)$ & 0.83 & $9.29(2.55)$ & $9.71(1.57)$ & 1.00 \\
\hline IQ (SD) & $91.65(17.20)$ & $97.79(18.33)$ & 0.22 & $92.57(16.77)$ & $87.14(10.96)$ & 0.54 \\
\hline \multicolumn{7}{|l|}{ CSBQ scores (SD) } \\
\hline Not optimally tuned to social situation & $13.76(5.10)$ & $12.24(5.49)$ & 0.29 & $9.00(6.33)$ & $8.57(5.74)$ & 0.90 \\
\hline Reduced contact and social interest & $10.05(5.55)$ & $7.05(4.54)$ & 0.04 & $9.71(5.77)$ & $7.71(3.45)$ & 0.46 \\
\hline $\begin{array}{l}\text { Orientation problems in time, place or } \\
\text { activity }\end{array}$ & $8.33(3.73)$ & $6.55(4.64)$ & 0.11 & $6.86(3.76)$ & $5.71(1.89)$ & 0.90 \\
\hline $\begin{array}{l}\text { Difficulties in understanding social } \\
\text { information }\end{array}$ & $7.65(4.07)$ & $7.00(3.81)$ & 0.55 & $8.29(3.50)$ & $7.71(3.15)$ & 0.90 \\
\hline Stereotyped behavior & $5.67(3.90)$ & $2.60(2.37)$ & 0.001 & $3.14(4.63)$ & $3.17(2.86)$ & 0.84 \\
\hline Fear of and resistance to changes & $3.92(2.03)$ & $3.27(2.41)$ & 0.28 & $2.29(1.98)$ & $3.29(1.89)$ & 0.26 \\
\hline Mental health care & $81 \%$ & $91 \%$ & 0.34 & $86 \%$ & $86 \%$ & 0.21 \\
\hline Medication & $60 \%$ & $38 \%$ & 0.12 & $29 \%$ & $29 \%$ & 1.00 \\
\hline
\end{tabular}

Bold values are statistically significant $(p<0.05)$

Table 3 Self-reported emotional and behavioral problems $(n=66)$ at wave 2

\begin{tabular}{ll}
\hline YSR scale & $\%$ (Sub)clinical range ${ }^{\mathrm{a}}$ \\
\hline Anxious depressed & $15.2 \%$ (of which $\mathrm{n}=6$ subclinical, and $\mathrm{n}=4$ clinical) \\
Withdrawn depressed & $18.2 \%$ (of which $\mathrm{n}=10$ subclinical, and $\mathrm{n}=2$ clinical) \\
Somatic complaints & $6.1 \%$ (of which $\mathrm{n}=0$ subclinical, and $\mathrm{n}=4$ clinical) \\
Attention problems & $18.2 \%$ (of which $\mathrm{n}=6$ subclinical, and $\mathrm{n}=6$ clinical) \\
Rule breaking behaviors & $4.5 \%$ (of which $\mathrm{n}=1$ subclinical, and $\mathrm{n}=2$ clinical) \\
Aggressive behaviors & $12.1 \%$ (of which $\mathrm{n}=5$ subclinical, and $\mathrm{n}=3$ clinical) \\
\hline
\end{tabular}

${ }^{a}$ Subclinical range $=\mathrm{t} 65-\mathrm{t} 70$; clinical range $\geq \mathrm{t} 70$

\section{Discussion}

The current follow-up study examined stability and predictors of comorbid psychiatric disorders in individuals with PDD-NOS. Firstly, we examined the rates of comorbid psychiatric disorders in childhood and in adolescence. The rates of individuals who had one or more comorbid psychiatric disorder in childhood $(81 \%)$ and adolescence (61\%) were similar to rates found in previous studies (Abdallah et al. 2011; Ghaziuddin et al. 1998; Leyfer et al. 2006; Simonoff et al. 2008; Van Steensel et al. 2013). In general, psychiatric comorbidity was rather stable $(63 \%)$; individuals who already had at least one comorbid psychiatric classification in childhood, usually still had at least one comorbid psychiatric classification in adolescence. One previous study concerning the stability of symptom levels of other psychiatric disorders from childhood to adolescence in a sample of individuals diagnosed with ASD found that symptoms of co-occurring psychiatric problems were persistent in individuals with ASD from childhood to adolescence (Simonoff et al. 2013). The current study added to that work by showing that both other psychiatric symptoms and other categorical psychiatric diagnoses can persist from childhood to adolescence. Changes in prevalence rates and transitions between types of comorbidity were examined and are discussed below. Due to the limited sample size, domain-specific stability of psychiatric comorbidity could not be tested.

The prevalence of one or more anxiety disorder in individuals with PDD-NOS, according to the DISC-IV-P, was significantly higher in childhood (55\%) than in adolescence $(31 \%)$. In the general population, also a decrease in anxiety from early to middle adolescence has been found (e.g. Van Oort et al. 2009), suggesting a similar developmental process. The rates for anxiety disorders in the individuals with PDD-NOS in the current study were quite high, although even higher rates $(84 \%)$ were reported in the literature (Muris et al. 1998). In the current study, among all anxiety disorders, the highest prevalence was found for SP at both assessment waves; $41 \%$ in childhood, 
and $26 \%$ in adolescence. This is in line with previous studies that also described SP as the most common anxiety disorder in children with ASD (Leyfer et al. 2006; Muris et al. 1998; Van Steensel et al. 2013) The current findings add to the existing literature, by showing that also in adolescence, SP is the most common anxiety disorder among individuals with ASD, although a significant drop was also found with 18 cases no longer meeting criteria for this disorder. Possibly, the finding of highly prevalent SP could be explained by the fact that we-and previous studies-used the parent as the informant; i.e. specific phobias might be most noticeable to parents, especially in childhood. For this reason, we also explored self-reported anxiety levels. These preliminary findings did not suggest higher self-reported levels of anxiety in adolescence. Yet clearly, further studies using self-reported anxiety are needed to clarify the most prevalent types of anxiety in children and adolescents with ASD (Muris et al. 1998).

The rate of MDD increased slightly from $8 \%$ in childhood to $11 \%$ in adolescence. These rates are in line with those known from the literature, although higher (i.e. $16 \%$ ) and much lower rates (i.e. $1 \%$ ) have also been reported among individuals with ASD (Leyfer et al. 2006; Simonoff et al. 2008; Mazefsky et al. 2011; Van Steensel et al. 2013; Witwer and Lecavalier 2010). In the general population, also an increase in depression from childhood to adolescence has been found (Maughan et al. 2013), suggesting a similar developmental process.

The rate of comorbid ADHD decreased from childhood (45\%) to adolescence (39\%). These relatively high rates are in line with previous studies (Goldstein and Schwebach 2004; Leyfer et al. 2006; Mazefsky et al. 2011), although lower rates have also been reported among individuals with ASD (Abdallah et al. 2011; Hanson et al. 2013; Simonoff et al. 2008; Van Steensel et al. 2013). The current study found a decrease for the hyperactivity type of ADHD and the combined type of ADHD in individuals with PDD-NOS from childhood to adolescence, but an increase for the inattentive type of ADHD in adolescence, with 15 new cases in adolescence. This change in the occurrence of ADHD in individuals with PDD-NOS is in line with the suggested trajectory of development of ADHD with hyperactivity at preschool age, more normoactive behavior during the early school years and a tendency to hypoactivity in early adolescence (Gillberg and Billstedt 2000). In adolescence, transition to secondary education increases attentional demands and peer pressures, with the potential to amplify previously unnoticed problems.

In the current study, criteria for ODD were met for $35 \%$ of the individuals in childhood and $27 \%$ of the individuals in adolescence. Simonoff et al. (2008) found similar rates (28\%) with the DISC in their study among 10-14 year old individuals with ASD, although much lower (i.e. $7 \%$;
Leyfer et al. 2006) as well as higher (i.e. $75 \%$; Witwer and Lecavalier 2010) rates of ODD have been reported in studies that used other diagnostic instruments. Criteria for $\mathrm{CD}$ were met for $10 \%$ of the individuals in childhood and $3 \%$ of the individuals in adolescence. The rate in adolescence is similar to the rate $(3 \%)$ found in the study of Simonoff et al. (2008) among 10-14 year old individuals with ASD, although much higher rates (i.e. $22 \%$ ) are reported among 3-17 year olds with ASD (Joshi et al. 2010). All individuals with CD in the current study also met the criteria for ODD at both $\mathrm{T} 1$ and $\mathrm{T} 2$.

Taken together, the overall prevalence of parent-reported psychiatric comorbidity decreased from childhood to adolescence. Variation in the prevalence of comorbid disorders across different studies may be explained by methodological differences in aspects such as methods of assessment and diagnosis, and how samples were constituted (i.e. differences in levels and types of care in different institutions). Our own data showed no particular transitions from one type of comorbidity to another; only 2 cases shifted from having an internalizing to an externalizing diagnosis, and one from an externalizing to an internalizing one. Although our dataset is limited, cross-domain transitions seem infrequent, and domain stability seems most common.

The current study suggested two predictors of stable psychiatric comorbidity from childhood to adolescence. Children with stable psychiatric comorbidity showed a higher childhood level of parent-reported stereotyped behavior and reduced contact and social interest. Post-hoc analyses also showed that parent-reported stereotyped behaviors were predictive for the persistent presence of either internalizing or externalizing disorders. Thus, our preliminary findings suggest that parent-reported stereotyped behaviors might be an indication for persistent comorbidity. There were no significant predictors for the persistent absence of comorbidity, although there probably was a lack of power to detect these, since these groups were very small. To our knowledge, no previous studies investigated childhood predictors of comorbidity in adolescence, so further research is needed to corroborate our findings.

Taken together, although the stability rate of any comorbid psychiatric classification was considerable $(63 \%)$, re-evaluation of psychiatric comorbidity in adolescence should be considered in clinical practice, since a reasonable amount of individuals no longer meet diagnostic criteria for a comorbid classification in adolescence or shifted from one comorbid diagnosis to another. Reduced social interest and stereotyped behavior as rated by parents might be considered as indicators of stable psychiatric comorbidity.

PDD-NOS itself can show different developmental trajectories. In the current literature, there are studies that 
show relative stability of ASD diagnosis (Jónsdóttir et al. 2007; Takeda et al. 2005); but also studies showing shifts within the spectrum and studies showing that some individuals appear to move out of the spectrum (Daniels et al. 2011; Kleinman et al. 2008; Turner and Stone 2007; for a review, please see Woolfenden et al. 2012). Of the 74 children with PDD-NOS participating in this last study, 22 no longer met criteria for PDD-NOS in adolescence. There are also children that don't meet criteria for ASD at a young age, but who do at an older age (i.e. in our larger cohort of 246 clinical referrals, 16 children did not meet PDD-NOS criteria in childhood, but did so in adolescence). Changes in comorbidity need to be interpreted in the context of these possible changes within ASD. For details on the stability of ASD within this sample, see Louwerse et al. (2015). Further research into the intertwined development of ASD symptomology and autistic and co-occurring psychiatric problems is warranted.

Our sample of children was diagnosed with PDD-NOS. But one may wonder how these findings apply to individuals diagnosed with ASD using current DSM 5 criteria. The children in our sample also were part of a larger study on phenotypic profiles of children with PDD (Greaves-Lord et al. 2013). This study has found that about $30 \%$ of the sample had a profile more in line with the more recent DSM-5 diagnosis of Social (Pragmatic) Communication Disorder. The reader should interpret our findings against this background.

Our wave 2 YSR self-report data was used to provide information on adolescents' internalizing comorbidities through post hoc exploration. Contrary to our expectations we found lower self-reported rates of anxiety rates $(15.2 \%)$ than parent-reported DISC-P wave 2 rates $(31.1 \%)$. We had expected to see higher self-reported than parent-reported rates of internalizing problems, given that adolescents might not openly share these emotions with their parents. In line with expectations, we found a somewhat higher rate of self-reported depressive symptoms (18.2\%-in the subclinical range) when compared to the parent-reported DISC-P wave 2 rate of $10.8 \%$. DISC-P data cannot be directly compared to YSR data due to the rather different properties of these instruments, and the lack of comparative research on these two measures. We hope these data provide some background information that helps to broaden the picture from our main analyses. Further research would be needed to profile the longitudinal trajectories of self-reported comorbidities in this group.

As discussed above, the current findings presented are quite preliminary, and should be interpreted against the background of some methodological limitations. Results are based on parental interviews in a relatively small sample of individuals with PDD-NOS with an average to high IQ who were referred to one particular center, thus clinicians should make careful considerations regarding their own specific clients, and further research on samples with more phenotypic variation in ASD severity and cognitive ability using multiple informants is needed. Also, only information on current medication in adolescence was obtained, without further details on medication history. Therefore, our finding that medication was not associated with later comorbidity should be further scrutinized in future research. Finally, since only 12 participants of the current sample were 18 years or older at the time of wave 2 data collection, it is not yet possible to shed further light on the adult outcomes of the current sample. Development from adolescence into adulthood is accompanied by many challenges regarding societal functioning (i.e. community and social participation, such as obtaining a job, living independently, and building intimate relationships). In a study of Myers et al. (2015), it was found that co-occurring behavioral difficulties in adolescents with ASD were associated with increased risk of social isolation in adolescence, but not with social or community participation in adulthood. This study did not investigate behavioral or emotional difficulties in adulthood, but one might assume that comorbid emotional and/or behavioral problems in adulthood may be affected by negative social/community outcomes, and may thus become more problematic over time. Future research is warranted to further examine the trajectories and determinants of comorbid psychiatric disorders of individuals with ASD into adulthood and later life.

Acknowledgments The authors thank the children and parents who participated in this project. This research was supported by a grant from the Sophia Foundation for Scientific Research (SSWO; Grant 586, 2009) and a grant from the NutsOhra Foundation (Grant 0803-53).

Author contribution CV was responsible for data collection, data analysis, interpretation of the results, and drafted the manuscript. AL, ME, JE, AG, FV, FCV participated in the design of the study, the interpretation of the data and manuscript development. KG participated in the design of the study, data analysis, interpretation of the results, manuscript development and supervised the overall study. All authors read and approved the final version of the manuscript.

\section{Compliance with Ethical Standards}

Conflicts of interest Kirstin Greaves-Lord is second author on the Dutch ADOS-2 manual, for which Yulius receives remuneration. Frank Verhulst is head of the department of Child and Adolescent Psychiatry at Erasmus MC, which publishes ASEBA materials and from which he receives remuneration.

Ethical Statement At wave 1, parents of the participating children signed informed consent forms prior to participation in the study. At wave 2 , both parents and adolescents signed the informed consent forms. This study was approved by the local Medical Ethics Committee (MEC-2008-388).

Open Access This article is distributed under the terms of the Creative Commons Attribution 4.0 International License (http://crea tivecommons.org/licenses/by/4.0/), which permits unrestricted use, 
distribution, and reproduction in any medium, provided you give appropriate credit to the original author(s) and the source, provide a link to the Creative Commons license, and indicate if changes were made.

\section{References}

Abdallah, M. W., Greaves-Lord, K., Grove, J., Nørgaard-Pedersen, B., Hougaard, D. M., \& Mortensen, E. L. (2011). Psychiatric comorbidities in autism spectrum disorders: Findings from a Danish Historic Birth Cohort. European Child and Adolescent Psychiatry, 20(11-12), 599-601.

Achenbach, T. M., \& Rescorla, L. A. (2001). Manual for the ASEBA school-age forms and profiles. Burlington: University of Vermont Research Center for Children, Youth \& Families.

Amone-P'Olak, K., Ormel, J., Oldehinkel, A. J., Reijneveld, S. A., Verhulst, F. C., \& Burger, H. (2010). Socioeconomic position predicts specialty mental health service use independent of clinical severity: The TRAILS study. Journal of the American Academy of Child and Adolescent Psychiatry, 49(7), 647-655.

APA. (2000). Diagnostic and statistical manual of mental disorders, 4th ed. text rev (DSMIV-TR). Washington, DC: American Psychiatric Association.

Arnold, L. E. (1996). Sex differences in ADHD: Conference summary. Journal of Abnormal Child Psychology, 24(5), 555-569.

Bittner, A., Egger, H. L., Erkanli, A., Jane Costello, E., Foley, D. L., \& Angold, A. (2007). What do childhood anxiety disorders predict? Journal of Child Psychology and Psychiatry, 48(12), 1174-1183.

Buitelaar, J. K., Van der Gaag, R. J., Klin, A., \& Volkmar, F. (1999). Exploring the boundaries of pervasive developmental disorder not otherwise specified: Analyses of data from the DSM-IV autistic disorder field trial. Journal of Autism and Developmental Disorders, 29, 33-43.

Bussing, R., Mason, D. M., Bell, L., Porter, P., \& Garvan, C. (2010). Adolescent outcomes of childhood attention-deficit/hyperactivity disorder in a diverse community sample. Journal of the American Academy of Child and Adolescent Psychiatry, 49(6), 595-605.

Costello, E. J., Mustillo, S., Erkanli, A., Keeler, G., \& Angold, A. (2003). Prevalence and development of psychiatric disorders in childhood and adolescence. Archives of General Psychiatry, 60(8), 837-844.

Dahl, R. E. (2004). Adolescent brain development: A period of vulnerabilities and opportunities. Annals of the New York Academy of Sciences, 1021, 1-22.

Daniels, A. M., Rosenberg, R. E., Law, J. K., Lord, C., Kaufmann, W. E., \& Law, P. A. (2011). Stability of initial autism spectrum disorder diagnoses in community settings. Journal of Autism and Developmental Disorders, 41(1), 110-121.

De Bruin, E. I., Ferdinand, R. F., Meester, S., de Nijs, P. F., \& Verheij, F. (2007). High rates of psychiatric co-morbidity in PDD-NOS. Journal of Autism and Developmental Disorders, 37(5), 877-886.

Dekker, M. C., Koot, H. M., Van der Ende, J., \& Verhulst, F. C. (2002). Emotional and behavioral problems in children and adolescents with and without intellectual disability. Journal of Child Psychology and Psychiatry, 43(8), 1087-1098.

Ferdinand, R. F., \& Van der Ende, J. (1998). Diagnostic Interview Schedule for Children IV. Parent-version. Rotterdam: Erasmus University Rotterdam, Department of Child and Adolescent Psychiatry.

Ghaziuddin, M., Weidmer-Mikhail, E., \& Ghaziuddin, N. (1998). Comorbidity of Asperger syndrome: A preliminary report. Journal of Intellectual Disability Research, 42(4), 279-283.
Gillberg, C., \& Billstedt, E. (2000). Autism and Asperger syndrome: Coexistence with other clinical disorders. Acta Psychiatrica Scandinavica, 102(5), 321-330.

Goldstein, S., \& Schwebach, A. J. (2004). The comorbidity of pervasive developmental disorder and attention deficit hyperactivity disorder: Results of a retrospective chart review. Journal of Autism and Developmental Disorders, 34(3), 329-339.

Goodwin, R. D., Fergusson, D. M., \& Horwood, L. J. (2004). Early anxious/withdrawn behaviours predict later internalising disorders. Journal of Child Psychology and Psychiatry, 45(4), 874-883.

Greaves-Lord, K., Eussen, M. L. J. M., Verhulst, F. C., Minderaa, R. B., Mandy, W., Hudziak, J. J., et al. (2013). empirically based phenotypic profiles of children with pervasive developmental disorders: Interpretation in the light of the DSM-5. Journal of Autism and Developmental Disorders, 43(8), 1784-1797.

Hankin, B. L., Abramson, L. Y., Moffitt, T. E., Silva, P. A., McGee, R., \& Angell, K. E. (1998). Development of depression from preadolescence to young adulthood: Emerging gender differences in a 10-year longitudinal study. Journal of Abnormal Psychology, 107(1), 128-140.

Hanson, E., Cerban, B. M., Slater, C. M., Caccamo, L. M., Bacic, J., \& Chan, E. (2013). Brief report: Prevalence of attention deficit/ hyperactivity disorder among individuals with an autism spectrum disorder. Journal of Autism and Developmental Disorders, 43(6), 1459-1464.

Hartman, C. A., Luteijn, E., Serra, M., \& Minderaa, R. (2006). Refinement of the Children's Social Behavior Questionnaire (CSBQ): An instrument that describes the diverse problems seen in milder forms of PDD. Journal of Autism and Developmental Disorders, 36(3), 325-342.

Hepburn, S. L., Stern, J. A., Blakeley-Smith, A., Kimel, L. K., \& Reaven, J. A. (2014). Complex psychiatric comorbidity of treatment-seeking youth with autism spectrum disorder and anxiety symptoms. Journal of Mental Health Research in Intellectual Disabilities, 7(4), 359-378.

Hurtig, T., Kuusikko, S., Mattila, M. L., Haapsamo, H., Ebeling, H., Jussila, K., et al. (2009). Multi-informant reports of psychiatric symptoms among high-functioning adolescents with Asperger syndrome or autism. Autism, 13(6), 583-598.

Jónsdóttir, S. L., Saemundsen, E., Asmundsdóttir, G., Hjartardóttir, S., Asgeirsdóttir, B. B., Smáradóttir, H. H., et al. (2007). Followup of children diagnosed with pervasive developmental disorders: Stability and change during the preschool years. Journal of Autism and Developmental Disorders, 37(7), 1361-1374.

Joshi, G., Petty, C., Wozniak, J., Henin, A., Fried, R., Galdo, M., et al. (2010). The heavy burden of psychiatric comorbidity in youth with autism spectrum disorders: A large comparative study of a psychiatrically referred population. Journal of Autism and Developmental Disorders, 40(11), 1361-1370.

Kleinman, J. M., Ventola, P. E., Pandey, J., Verbalis, A. D., Barton, M., Hodgson, S., et al. (2008). Diagnostic stability in very young children with autism spectrum disorders. Journal of Autism and Developmental Disorders, 38(4), 606-615.

Leyfer, O. T., Folstein, S. E., Bacalman, S., Davis, N. O., Dinh, E., Morgan, J., et al. (2006). Comorbid psychiatric disorders in children with autism: Interview development and rates of disorders. Journal of Autism and Developmental Disorders, 36(7), 849-861.

Louwerse, A., Eussen, M. L. J. M., Van der Ende, J., de Nijs, P. F. A., Van Gool, A. R., Dekker, L. P., et al. (2015). ASD symptom severity in adolescence of individuals diagnosed with PDD-NOS in childhood: Stability and the relation with psychiatric comorbidity and societal participation. Journal of Autism and Developmental Disorders. doi:10.1007/s10803-015-2595-2. 
Luteijn, E., Jackson, S., Volkmar, F. R., \& Minderaa, R. B. (1998). Brief report: The development of the Children's Social Behavior Questionnaire: Preliminary data. Journal of Autism and Developmental Disorders, 28(6), 559-565.

Maughan, B., Collishaw, S., \& Stringaris, A. (2013). Depression in childhood and adolescence. Journal of the Canadian Academy of Child Adolescent Psychiatry, 22(1), 35-40.

Mazefsky, C. A., Kao, J., \& Oswald, D. P. (2011). Preliminary evidence suggesting caution in the use of psychiatric self-report measures with adolescents with high-functioning autism spectrum disorders. Research in Autism Spectrum Disorders, 5(1), 164-174.

Muris, P., Steerneman, P., Merckelbach, H., Holdrinet, I., \& Meesters, C. (1998). Comorbid anxiety symptoms in children with pervasive developmental disorders. Journal of Anxiety Disorders, 12(4), 387-393.

Myers, E., Davis, B. E., Stobbe, G., \& Bjornson, K. (2015). Community and social participation among individuals with autism spectrum disorder transitioning to adulthood. Journal of Autism and Developmental Disorders, 45, 2373-2381.

Petersen, A. C., Sarigiani, P. A., \& Kennedy, R. E. (1991). Adolescent depression: Why more girls? Journal of Youth and Adolescence, 20(2), 247-271.

Schroeder, J. H., Weiss, J. A., \& Bebko, J. M. (2011). CBCL profiles of children and adolescents with Asperger syndrome: A review and pilot study. Journal on Developmental Disabilities, 17(1), 26-37.

Shaffer, D., Fisher, P., Lucas, C. P., Dulcan, M. K., \& Schwab-Stone, M. E. (2000). NIMH Diagnostic Interview Schedule for Children Version IV (NIMH DISC-IV): Description, differences from previous versions, and reliability of some common diagnoses. Journal of the American Academy of Child and Adolescent Psychiatry, 39(1), 28-38.

Simonoff, E., Jones, C. R., Baird, G., Pickles, A., Happé, F., \& Charman, T. (2013). The persistence and stability of psychiatric problems in adolescents with autism spectrum disorders. Journal of Child Psychology and Psychiatry, 54(2), 186-194.

Simonoff, E., Pickles, A., Charman, T., Chandler, S., Loucas, T., \& Baird, G. (2008). Psychiatric disorders in children with autism spectrum disorders: Prevalence, comorbidity, and associated factors in a population-derived sample. Journal of the American Academy of Child and Adolescent Psychiatry, 47(8), 921-929.

Steenhuis, M. P., Serra, M., Minderaa, R. B., \& Hartman, C. A. (2009). An Internet version of the Diagnostic Interview Schedule for Children (DISC-IV): Correspondence of the ADHD section with the paper-and-pencil version. Psychogical Assessesment, 21(2), 231-234.

Takeda, T., Koyama, T., Kanai, C., \& Kurita, H. (2005). Clinical variables at age 2 predictive of mental retardation at age 5 in children with pervasive developmental disorder. Psychiatry and Clinical Neurosciences, 59(6), 717-722.

Turner, L. M., \& Stone, W. L. (2007). Variability in outcome for children with an ASD diagnosis at age 2. Journal of Child Psychology and Psychiatry, 48(8), 793-802.

Van Haasen, P. P., De Brun, E. E. J., Pijl, Y. J., Poortinga, Y. H., Spelberg, H. C., \& Van der Steene, G. (1986). WISC-R, Wechsler Intelligence Scale for Children-Revised, Nederlandse uitgave. Deel I. Testinstructie; Deel II. Scoring en Normen; Deel III. Verantwoording. Lisse: Swets \& Zeitlinger.

Van Oort, F. V. A., Greaves-Lord, K., Verhulst, F. C., Ormel, J., \& Huizink, A. C. (2009). The developmental course of anxiety symptoms during adolescence: The TRAILS study. Journal of Child Psychology and Psychiatry, 50(10), 1209-1217.

Van Steensel, F. J., Bögels, S. M., \& De Bruin, E. I. (2013). Psychiatric comorbidity in children with autism spectrum disorders: A comparison with children with ADHD. Journal of Child and Family Studies, 22(3), 368-376.

Wechsler, D. (1974). Wechsler intelligence scale for children-revised, manual. New York: The Psychological Corporation.

Witwer, A. N., \& Lecavalier, L. (2010). Validity of comorbid psychiatric disorders in youngsters with autism spectrum disorders. Journal of Developmental and Physical Disabilities, 22, 367-380.

Woolfenden, S., Sarkozy, V., Ridley, G., \& Williams, K. (2012). A systematic review of the diagnostic stability of autism spectrum disorder. Research in Autism Spectrum Disorders, 6, 345-354. 